\title{
AS NARRATIVAS COMO UMA POSSIBILIDADE PARA O PROCESSO DE ENSINO E APRENDIZAGEM EM CONTEXTO INTERCULTURAL
}

\author{
THE NARRATIVES AS A POSSIBILITY FOR THE TEACHING AND LEARNING \\ PROCESS IN AN INTERCULTURAL CONTEXT
}

\author{
G. B. SOUZA' ${ }^{1 *}$ e L. M. B. PACHECO ${ }^{2}$ \\ 1 Universidade Estadual de Campinas/SP, Programa de Pós-Graduação em Educação, Brasil. \\ 2 Universidade Estadual de Feira de Santana/ BA, Departamento de Educação, Brasil
}

AR T I C LEINFO

Article history:

Received 2018-07-01

Accepted 2018-12-20

Available online 2018-12-21
Palavras-chave: Cultura Indígena; Narrativas; Ensino Intercultural.

Keywords: Indigenous Culture; Narratives; Intercultural teaching.

*Autor correspondente:

E-mail:gabibarbosa_fsa@hotmail.com

RESUMO. O presente estudo objetiva evidenciar o papel das narrativas como uma possibilidade para o processo de ensino e aprendizagem em contexto intercultural. Inicialmente apresenta-se o contexto histórico das políticas públicas direcionadas para a educação escolar indígena. Posteriormente, discute-se sobre a função das narrativas para o processo de ensino e aprendizagem em contexto intercultural a partir de depoimentos de membros do povo indígena Pataxó Hãhãhãi. Nessa perspectiva, destaca-se a importância do trabalho pedagógico organizado através dos contos do povo indígena Pataxó Hãhãhãi para o ensino formal nessa comunidade, possibilitando a estes o conhecimento de valores da sua própria cultura, bem como o estudo da estrutura formal da língua, através do ensino/aprendizagem de gêneros e tipologias textuais. Considera-se que o trabalho com gêneros textuais narrativos poderá possibilitar aos professores indígenas melhor mediação entre o trabalho com a língua e os saberes culturais, cotejando os conteúdos universais e a transmissão de narrativas locais.

ABSTRACT. The present study aims to highlight the role of narratives as a possibility for the teaching and learning process in a intercultural context. Initially, the historical context of the public policies directed towards indigenous school education is presented. Subsequently, it is discussed the function of the narratives for the teaching and learning process in a intercultural context, based on statements made by members of the Pataxó Hãhãhãi indigenous people. In this perspective, the importance of the pedagogical work organized through the tales of the Pataxó Hãhãhãi indigenous people for the formal education in this community is highlighted, enabling them to know the values of their own culture, as well as the study of the formal structure of the language through of teaching / learning of genres and textual typologies. It is considered that the work with narrative textual genres may enable indigenous teachers for better mediation between working with the language and the cultural knowledge, comparing the universal contents and the transmission of local narratives.

\section{INTRODUÇÃO}

O grupo de Pesquisa Desenvolvimento Humano e Processos Educativos (DEHPE), da Universidade Estadual de Feira de Santana/BA tem realizado ações de ensino, pesquisa e extensão entre a universidade e a escola básica indígena através do projeto de extensão 
"Narrativas e Representações". O referido projeto tem como objetivos levantar (através de informações orais) a cultura local de comunidade indígena, promover situações de reflexão e registro sobre a cultura e o saber local, promover atividades pedagógicas sobre gêneros textuais (narrativas), produzir representações gráficas e textuais a partir do saber local e contribuir para a formação continuada de professores indígenas ou não-indígenas através de diálogos interculturais.

Este estudo é resultante do referido projeto de pesquisa/ensino/extensão realizado em uma comunidade indígena, e objetiva evidenciar a importância das narrativas como uma possibilidade para o processo de ensino-aprendizagem em contexto intercultural.

Inicialmente, aborda-se o contexto histórico das políticas públicas direcionadas para a educação escolar indígena e a formação de professores indígenas. Posteriormente, discute-se sobre a importância das narrativas para o processo de ensino-aprendizagem em contexto intercultural a partir de depoimentos de membros do Povo Indígena Pataxó Hãhãhãi. Por fim apresenta-se as considerações e as referências bibliográficas que fundamentaram a construção deste estudo.

\section{CONTEXTO HISTÓRICO: EDUCAÇÃO ESCOLAR INDÍGENA}

Desde o século $\mathrm{XVI}$, os povos indígenas conviveram com políticas que só buscavam a homogeneização da sociedade, advindas inicialmente dos missionários jesuítas através da catequização e, posteriormente, pelo Serviço de Proteção ao Índio (SPI) que objetivava a integração forçada dos índios a sociedade nacional. De acordo com Bergamaschi e Medeiros (2010, p.58), a partir da criação do Serviço de Proteção ao Índio, em 1910:

Os gentios foram colocados sob a tutela do Estado, que desde o advento da República passou a atuar de forma mais incisiva para territorializar, civilizar e integrar os povos indígenas na chamada sociedade nacional.

O processo de colonização do Brasil, assim como a formação do Estado Nacional e, hoje, a globalização ferem o direito a autonomia e ao processo identitário dos grupos indígenas. Oliveira e Nascimento (2012, p. 769) refletem sobre a ação do SPI, a partir de um ideário positivista de progresso nacionalista que intencionou subjugar os povos indígenas. Segundo eles, o objetivo era "promover um encontro pacífico destes com a civilização, tornando-os aptos para o trabalho com vistas ao progresso e modernização da nação". Estes povos indígenas foram/são vistos como uma categoria fadada à extinção, e para estes eram asseguradas por leis, políticas assimilacionistas como forma de integrá-los em uma cultura nacional homogênea.

Em 1967, o SPI foi substituído pela Fundação Nacional do Índio (FUNAI). De acordo com Oliveira e Nascimento (2012), assim como o SPI, a FUNAI também se orientava pelas políticas de integração dos povos indígenas à nação. No entanto, os autores ressaltam que 
diferentemente do SPI, a FUNAI reconheceu a importância das línguas nativas nos processos de alfabetização dos indígenas. Foi nessa perspectiva, que em 1970, a FUNAI estabeleceu relação com o Summer Institute of Linguistics (SIL), a qual de acordo com Oliveira e Nascimento (2012, p.772), permitiu surgir "[...] os cursos de formação de monitores bilíngues, cuja principal inovação residiu na utilização dos próprios indígenas como professores auxiliares [...]". Os autores destacam que:

[...] Mesmo subordinado ao objetivo de assimilação, o uso das línguas nativas, fazendo surgir a figura do professor indígena (ainda que auxiliar), favoreceria, a posteriori, o desenvolvimento dos projetos de educação escolar dos índios pautados na ideia de autonomia e na construção do protagonismo indígena num modelo educativo diferenciado, mais adequado aos interesses societários de suas comunidades.

Nota-se que até a década de 1970, a educação indígena foi marcada por imposições arbitrárias, na busca de que esses assimilassem a cultura considerada dominante. A partir do referido período as práticas educacionais indígenas começaram a ir contra essas políticas, na busca de mudar a situação política e educacional que lhes eram impostas (BERGAMASCHI e MEDEIROS, 2010).

Considera-se que o surgimento da figura do professor indígena a partir da atuação da FUNAI, assume papel relevante, visto que "estes podem fazer de suas escolas e de seus atos educacionais processos formadores que expressem a afirmação de suas culturas" (CAVALCANTE, 2003, p. 15). Ressalta-se que naquele momento, a figura do professor indígena assumia a função de auxiliar nas escolas indígenas, mas já se configura em uma iniciativa importante para pensar a construção de uma educação própria indígena.

Ao refletir sobre esse novo contexto, Oliveira e Nascimento (2012, p.772) ressaltam que "a prerrogativa das ações educativas passou da FUNAI para o MEC, por meio do Decreto n. 26, de 1991", o que retirou da FUNAI, várias de suas atribuições. Até o momento, as ações educativas dos povos indígenas foram regulamentadas por dois órgãos indigenistas, SPI e FUNAI, e passa a ser regulamentado pelo Ministério da Educação (MEC), junto com o desafio de se pensar uma educação ao mesmo tempo formal e universal, cultural e local. Foi nessa perspectiva, que nas últimas décadas do século $X X$, aconteceram mudanças significativas no que se refere ao âmbito das políticas educativas voltadas para os povos indígenas.

O "Referencial Curricular Nacional para as Escolas Indígenas (RCNE/Indígena)" (MEC/SECAD, 2005a). Este documento contempla uma educação específica, diferenciada e de qualidade construída em conjunto com os povos indígenas. Os Guaranis, por exemplo, foram tradicionalmente resistentes à educação escolar devido à ameaça que esta representava à cosmologia dos povos indígenas. Atualmente recorrem a uma educação escolar específica e diferenciada, buscam se instrumentalizar para melhor compreender os não-índios, a fim de estabelecer uma interação mais simétrica com a sociedade envolvente. 
Segundo Bergamaschi (2007, p.197) os povos Guarani defendem "práticas escolares que buscam constituir um modo próprio de ensinar, em diálogo com [...] a educação tradicional e a cosmologia desse povo."

Desde a Constituição de 1988, vem se consolidando o entendimento de que a educação escolar precisa levar em conta o contexto de diversidade sociocultural de seus alunos. Se a legislação está sempre sendo revista e melhorada, por outro lado, na prática, há muitos conflitos e contradições vividas na escola.

Camargo e Albuquerque (2003) analisam a construção do projeto pedagógico dos Xavantes, denunciando as tensões culturais vivenciadas nas escolas e nas comunidades. Weigel (2003) se pergunta por que um povo indígena lutaria por escolas, já que este pode ser um espaço ambivalente e contraditório, chegando à conclusão que:

Tal processo é determinado por relações políticas, relações de força e condições materiais, no qual os segmentos indígenas, dentre eles os Baniwa, operam mudanças em: sua cosmologia, suas concepções míticas e estéticas, sua magia, seus rituais, suas bases materiais e línguas, apropriando-se - mas também recriando e reelaborando, de acordo com critérios e paradigmas de suas próprias culturas - dos elementos da cultura dominante. (WEIGEL, 2003, p.5)

A Constituição Federal de 1988 e a Lei de Diretrizes e Bases da Educação Nacional (LDBEN) são marcos no rompimento com a política assimilacionista que era imposta aos índios, ao assegurar aos povos indígenas o direito à prática de suas culturas próprias, bem como, o direito de afirmarem seus valores culturais, línguas, costumes, tradições e crenças. A Constituição Federal (BRASIL, 1988, p.37) assegura em seu artigo 231, aos povos indígenas o reconhecimento de "sua organização social, costumes, línguas, crenças e tradições, e os direitos originários sobre as terras que tradicionalmente ocupam, competindo à União demarcá-las, proteger e fazer respeitar todos os seus bens". O referido documento assegura aos povos indígenas o direito de afirmarem seus valores culturais, línguas, costumes, tradições e crenças.

A UNESCO, em 2003, criou uma convenção para reconhecimento do patrimônio imaterial da humanidade e incentivo ao registro de bens. Segundo Pelegrini e Funari (2008, p.8):

A relevância dessa [...] disposição se justifica pela dimensão que os bens imateriais ou intangíveis assumem na compreensão da natureza e das visões de mundo das sociedades humanas [...]. Ao usufruirmos formas singulares de celebração e conhecimento nós retomamos parte de nossas identidades comuns. A transmissão de saberes às novas gerações e a perspectiva de valorizá-los tendem a contribuir para a elevação de nossa autoestima e para a retomada de tradições milenares.

O respeito à diversidade, à interculturalidade se impõe e toma-se como diretriz educacional a observância dos saberes identitários. A LDBEN (BRASIL, 1996), assegura em seu Artigo 78, que: 
O Sistema de Ensino da União, com a colaboração das agências federais de fomento à cultura e de assistência aos índios, desenvolverá programas integrados de ensino e pesquisa, para oferta de educação escolar bilíngue e intercultural aos povos indígenas, com os seguintes objetivos: I proporcionar aos índios, suas comunidades e povos, a recuperação de suas memórias históricas; a reafirmação de suas identidades étnicas; a valorização de suas línguas e ciências. II - garantir aos índios, suas comunidades e povos, o acesso às informações, conhecimentos técnicos e científicos da sociedade nacional e demais sociedades indígenas e não índias.

A LDBEN (BRASIL, 1996) reafirmou pontos que já foram contemplados na Constituição Federal de 1988 e trouxe aspectos inovadores para o contexto da educação escolar indígena, tais como o estabelecimento de uma educação escolar bilíngue e intercultural dos povos indígenas, com currículo, projeto pedagógico, material didático e formação de professores diferenciada. Os referidos documentos representam avanços adquiridos pelos povos indígenas, o que representa uma legislação educacional que contempla diferentes culturas. A educação escolar passa a ser um direito garantido às comunidades indígenas, bem como uma formação diferenciada para os professores indígenas. De acordo com Monte (2000, p.18):

[...] os professores indígenas vêm tentando reagir às condições anteriores impostas pelas escolas das agências que atuam no contato, reforçando as suas vozes agora na qualidade de autores. Concebem a educação não como oportunidade para a dominação e a conquista, e sim para a transformação dos conquistados em conquistadores, sujeitos políticos, usuários ativos que buscam o controle do meio e da mensagem.

A educação nesse contexto assume papel de possibilitar a problematização e reflexão de uma realidade subalternizada que ao longo de décadas se fez presente. Hoje considera-se que a educação intercultural deve contemplar uma ampla gama de conhecimentos e relações locais e universais, visto que as comunidades indígenas possuem sabedoria própria para ser comunicada, apesar de que por muito tempo esta não foi considerada no âmbito das políticas educacionais brasileiras. No entanto, faz-se relevante destacar que esta foi uma conquista a partir das lutas indígenas, e que mesmo diante de conquistas legais, as comunidades indígenas ainda sofrem dificuldades para construírem uma educação diferenciada, ao considerar o contexto de colonização, assimilação à que foram e são expostos.

Questiona-se como tem se dado a formação dos professores indígenas para atender a demanda da educação intercultural? De acordo com os Referenciais para a formação de professores indígenas (BRASIL, 2002, p.9) "entre os muitos desafios que enfrentam os povos indígenas para a progressiva qualificação de sua educação escolar, está o da preparação de professores indígenas no magistério intercultural". O referido documento ressalta que "a proposta de uma escola indígena[...]só será viável se os próprios índios[...]estiverem à frente do processo como professores e gestores da prática escolar". 
Nota-se a importância da formação dos professores indígenas, para atuarem em suas comunidades promovendo uma educação intercultural e um possível reposicionamento da influência da cultura hegemônica revestida em saber universal. O saber escolar perpetua um "currículo oculto", sua tomada de consciência, revela a complexidade desta proposta e a função crucial do protagonista indígena no ato educativo. Segundo Díaz-Barriga, (2006, 13):

O currículum oculto permite reconhecer que na prática escolar é gerado um conjunto de aprendizagens [...] e o desenvolvimento de valores [...]. Essa abordagem necessitará encontrar eco nas estratégias didáticas, na forma como se abordam os conteúdos no aspecto cognitivo e na coerência que existe entre valores, textos e incluso imagens [...]. se deve promover uma reflexão sobre como tais valores se expressam no meio social [...]" (tradução própria).

Faz-se necessário que os professores indígenas se apropriem das ferramentas e discurso educacional para que possam propor um currículo propriamente intercultural. $\mathrm{O}$ currículo deve contemplar os saberes tradicionais da comunidade associados ao conhecimento de outras cultural. Um indígena, Professor Kateyuve, citado por Monte (2000, 22) conta: "Nós já tivemos aula de história que começou com a história dos portugueses [...]. Isso é importante. Mas[...]demora muito [...]. Nesse meio [...]. Fica arriscado se perder pelo caminho [...]. Para estudar história é melhor sair da aldeia e partir para o mundo".

De acordo com Monte (2000, p.18) "assim são renovados não só os objetivos e conteúdos curriculares, mas, sobretudo, os métodos que orientam os processos de ensinoaprendizagem e o que é selecionado e transformado em conhecimento escolar". Busca-se a construção de uma educação contextualizada com a realidade sociocultural dos educandos, de forma a possibilitar a construção de aprendizagens significativas para uma atuação participativa e reflexiva na sociedade.

Sobre este paradoxo, filósofos como Althusser e Albuquerque (1992), e educadores como Paulo Freire $(1992,2005)$, se posicionaram, alertando sobre a dupla função da instituição educacional, que ao mesmo tempo em que abre possibilidades para a aprendizagem e crescimento, também submete ao status quo. Não é fácil resolver tal contradição, mas Freire (1992) propõe uma "Pedagogia da Esperança" como uma retomada da "Pedagogia do Oprimido" publicada pela primeira vez em 1970. Ele já sinalizava a perspectiva de uma educação para a autonomia, como um ideal a ser atingido, como um convite ao protagonismo.

\section{METODOLOGIA}

Este estudo constitui-se parte das reflexões realizadas na dissertação de Souza (2016) junto ao Programa de Pós-Graduação em Educação da Universidade Estadual de Feira de Santana - Bahia, a qual objetivou analisar quais as funções dos contos fantásticos para a cultura indígena Pataxó Hãhãhãi. 
O povo Pataxó Hãhãhãi reside na Aldeia Indígena Caramuru Paraguaçu, localizada em Pau-Brasil no sul do Estado baiano. O referido povo é composto por diferentes grupos étnicos que se juntaram em prol da luta pelo território, a saber: Baenã, Pataxó Hãhãhãi, Kamacã, Tupinambá, Kariri-Sapuiá, além de outras etnias que vêm se juntando devido ao contato intercultural com outros povos indígenas e com a sociedade envolvente.

Para realização da pesquisa, foram entrevistados membros do Povo Pataxó Hãhãhãi. Os informantes são anciões e adultos das diferentes etnias que compõem este povo, considerados por eles como conhecedores das narrativas da comunidade local. A pesquisa foi financiada pela Fundação de Amparo à Pesquisa do Estado da Bahia (FAPESB). $O$ projeto de pesquisa foi analisado e aprovado para execução pelo Comitê de Ética em Pesquisa (CEP), da Universidade Estadual de Feira de Santana e pela Comissão Nacional de Ética em Pesquisa (CONEP), por atender a todos os princípios bioéticos para pesquisa envolvendo seres humanos, conforme a Resolução oํ 466/12 (CNS). Encontra-se registrado nas referidas instituições com o CAAE: 39143814.5.0000.0053. Para realização da coleta de dados, a Fundação Nacional do Índio (FUNAI) autorizou o ingresso na terra indígena da Aldeia Caramuru Paraguaçu, através do processo no 08620.008303/2015-70.

Os membros da comunidade foram convidados a colaborar com a pesquisa $e$ informados sobre o Termo de Consentimento Livre e Esclarecido (TCLE), no qual estão especificados os objetivos, aspectos metodológicos, riscos e benefícios de sua participação na pesquisa e puderam se posicionar quanto a aceitar ou não colaborar com esse estudo. Foi dada aos participantes a opção em divulgar seus nomes ou não, entendendo a importância de situar que os depoimentos relatados nesse estudo constituem-se testemunhos de membros do povo indígena Pataxó Hãhãhãi quanto às suas vivências culturais. Os depoimentos foram coletados em situações do cotidiano da aldeia de forma previamente combinada. As falas foram transcritas sem maiores intervenções, tentando fixar o texto como ação da fala (LANGDON, 1999).

\section{AS NARRATIVAS COMO POSSIBILIDADE PARA O PROCESSO DE ENSINO APRENDIZAGEM INTERCULTURAL}

Para os povos indígenas, o contato com a sociedade envolvente e a depreciativa negação de seus saberes, valores, línguas, além das invasões de seu território têm ocasionado mudanças em seus costumes e comportamento. Por outro lado, eles buscam reafirmar a partir da reconquista do seu território e da prática de seus rituais, mesmo com algumas mudanças de seus hábitos, valores e cosmovisões. Já houve tempo que os indígenas se fecharam para a educação formal. Hoje ela tem sido almejada, mas no sentido de garantir um processo de ensino-aprendizagem contextualizado com a cultura local. 
O ambíguo papel da educação e a ação homogeneizadora da interação com a sociedade envolvente alerta a população indígena para o seu papel como protagonista. A importância da cultura e identidade é destacada na fala de Jisélia Oliveira dos Santos, membro da etnia Kariri-Sapuiá, para quem:

\begin{abstract}
A cultura... principalmente pra nós... povos indígenas... é muito importante [...] o índio tem que ter a cultura e as raízes dele... agora não é porque ele não tá vestido ou trajado diariamente... não quer dizer que ele não vai ser índio... não... tá na sua identidade... na sua consciência... ele não pode deixar os seus atos... os seus momentos... mas a cultura vai tá sempre acompanhado com o nosso povo... com a gente mesmo no nosso dia a dia... não importa onde a gente esteja... você vai ser sempre o que você é... você não vira índio... você nasce índio... as suas raízes tá ali... você pode tá longe... mas seu pensamento tá em seu povo... na sua identidade [...] a cultura vai ser sempre importante e fundamental na nossa aldeia... no nosso povo... no nosso convívio no dia a dia.
\end{abstract}

Compreende-se que o Povo Pataxó Hãhãhãi sofreu mudanças em seu modo de vida devido às várias situações de contato e conflito a que foram submetidos pela sociedade envolvente. No entanto, entende-se que mesmo diante de tal situação, buscam manter seus valores culturais que se encontram presentes em sua memória e ligadas ao seu território social. Justo (2012, p. 39), ao se fundamentar no conceito de memória de Le Goff (1994), reflete sobre a relação entre cultura e sociedade:

Memória e sociedade são os pilares que constituem a cultura. Memória, como mecanismo de retomada e compreensão do objeto de estudo, mitos, contos e lendas, enquanto elementos significativos da literatura oral e escrita. Sociedade, como ambiente onde se criam, reproduzem ou morrem os significados dos referidos relatos construídos e reconstruídos pela memória, dinamizando, modificando e/ou perpetuando a cultura e seu alcance.

Nessa perspectiva, Justo (2012, p. 45) destaca a importância da memória coletiva como capaz de garantir "a identidade do indivíduo, como pertencente a um determinado grupo e contribui para a coesão e unidade deste". A narrativa é vista enquanto elemento significativo da memória cultural e social. Sua importância para o povo Pataxó Hãhãhãi é enfatizada por Aluíso Costa Vieira, membro da etnia Kariri-Sapuiá:

[...] a consideração desses conto pra gente... ela é muito especial... porque é a partir daí que a gente consegue entender um pouco do que é a luta indígena... o sofrimento dos nossos anciões... o que passaram... de alguns ancestrais que já se foi... então isso aí pra gente... na maioria das vezes ajuda a gente no conhecimento da cultura e nos dá mais força ainda... pra gente lutar pelos objetivos da nossa comunidade... principalmente na luta territorial que é uma coisa assim... um marco na história da gente.

Compreende-se que a memória coletiva, materializada em narrativas, possibilita a organização social de um povo através do conhecimento da história local e de seus 
significados, os quais se encontram ligados ao território em que ocorreram esses fatos. Pensando especificamente no Povo Pataxó Hãhãhãi, compreende-se, a partir da fala desse informante, que as narrativas são relevantes ao conhecimento da cultura local, constituindose como mecanismo de luta social na busca de seus direitos culturais e territoriais.

Severi (2000, p.147), ao discutir sobre os vários tipos de narrativa e a construção de memórias sociais, aborda que:

Existem dois modos de construir memórias sociais: um opera através da narração (e renovação contínua) de uma série de histórias; o outro, sempre vinculado à elaboração da memória ritual, tende a criar um número relativamente estável de imagens cada vez mais complexas, cada vez mais "carregadas" de significados e cada vez mais persistentes ao longo do tempo.

Nota-se que existem modos de construir memórias sociais, e as narrativas, sejam elas orais, escritas ou imagéticas, são mecanismos de significações culturais. Esse é o contexto em que este estudo se insere, visto que os contos e outras narrativas são considerados enquanto materialidades da memória capazes de criar significados culturais e identitários, sejam eles individuais ou coletivos. Halbwachs (2003, p. 71) diferencia memória coletiva de memória individual:

As lembranças [podem] se organizar de duas maneiras: tanto se agrupando em torno de uma determinada pessoa, que as vê de seu ponto de vista, como se distribuindo dentro de uma sociedade grande ou pequena, da qual são imagens parciais. Portanto, existiriam memórias individuais e [...] memórias coletivas. Em outras palavras, o indivíduo participaria de dois tipos de memórias. [...] Por um lado, suas lembranças teriam lugar no contexto de sua personalidade ou de sua vida pessoal. [...] Por outro lado, em certos momentos, ele seria capaz de se comportar simplesmente como membro de um grupo que contribui para evocar e manter lembranças impessoais, na medida em que essas interessam ao grupo.

Nessa perspectiva, Halbwachs (2003) distingue as memórias individuais, que são construções do indivíduo em meio a sua vida pessoal, e a memória coletiva que o indivíduo constrói enquanto sujeito do grupo e representante da coletividade. No entanto, Halbwachs (2003, p.72) enfatiza que a memória individual não é construída de forma isolada e fechada, visto que "para evocar seu próprio passado, em geral a pessoa precisa recorrer às lembranças de outras, e se transporta a pontos de referência que existem fora de si, determinados pela sociedade". Corroborando com essa questão, Araripe (2004, p. 114) enfatiza que:

Há, [...] na memória [...] um veio para se obter uma identidade e os laços de pertencimento com a comunidade onde se insere. Com todas as implicações que acompanham as discussões sobre identidade cultural no presente momento, ainda assim acreditamos dever existir uma relação de reconhecimento e pertencimento - de identidade, daquilo que se constitui como patrimônio com a história do seu povo e as suas práticas cotidianas. 
Entende-se a memória como algo estruturante da cultura, visto que proporciona a construção de laços identitários de pertencimento com o território em que o sujeito vive, seja ela individual ou coletiva. Maura Rosa Titiá, anciã da etnia Baenã, reflete sobre a importância da memória e das narrativas na luta territorial do Povo Indígena Pataxó Hãhãhãi, ao dizer que:

Quando nós voltemo pra nossa terra... de ocupação... a gente já tinha a história viva... tinha documento lá na Federal e tudo... tinha mais força de lutar né? aí tava os índio mais velho... os antigo tava tudo vivo... eles contava história... em Brasília tinha nossa história e tava registrado em documento pra mostrar lá na FUNAI que nós tava atrás de nossa terra... de nossa terra onde viveu... tinha o lugar de nosso povo do passado... aí às vezes se a gente não contar essas história pra nossos neto... como é que eles vai ficar mais tarde? muitos fala aí: os índio acabou e não tem mais índio... mas não olha como nós tamo viveno... a resistência da gente... hoje nós tamo aqui dentro da aldeia... voltemo pra nossa origem.

A memória e as narrativas permitem ao povo Pataxó Hãhãhãi construir uma relação de pertencimento ao seu território de origem e uma identidade cultural coletiva, vinculada ao seu patrimônio social, histórico e cultural. A memória e a narrativa têm-se configurado em mecanismos de resistência dos povos indígenas diante da ação de submissão e de desvalorização de sua cultura na interação com a sociedade brasileira. Aspecto este que pode ser contemplado no processo de ensino-aprendizagem como forma de ressignificar a instituição escolar, construindo assim uma educação contextualizada e capaz de possibilitar um ensino intercultural.

A ressignificação da instituição escolar, na busca por uma educação diferenciada, é almejada pelo Povo Pataxó Hãhãhãi. Maria Muniz, membro da etnia Tupinambá e primeira professora indígena do Povo Pataxó Hãhãhãi, ao ser questionada a propósito do papel da escola em contextos indígenas, ela relata que

O papel da minha escola tá muito longe pelo que quero... e o que penso... e o que eu desejo... porque eu penso muito em uma escola diferenciada de verdade... e ainda a gente ainda tem muita história do Estado ainda é... [...] tenta ainda dizer ainda como é que os índios têm que fazer... como é que nossos professores tem que ensinar... porque nossos professores é capaz de ensinar da forma que a gente acha que é muito bom pra nosso povo e não deixando... sendo uma escola diferenciada e não deixando de falar um pouco de lá de fora... porque a gente tem que enfrentar barreiras difíceis também... e esses alunos também tem que ter um pouco da preparação de lá de fora pra ver como é que pode enfrentar... agora contando que a nossa escola tem que esquecer esses livros que vem de lá e quem faz lá da forma que faz... e lembrar que nós... nossa escola e nossa aldeia tem muita história bonita... tem muitos anciões que ainda conta muita coisa e que isso tem que ter um grande aproveitamento.

A partir desse relato, entende-se que a construção de uma educação escolar diferenciada, mesmo sendo um direito legal, é um processo marcado por dificuldades no que se refere ao diálogo dos saberes socialmente construídos e o acervo cultural indígena. Nota-se que a escola, ao ser inserida numa comunidade indígena, abarca pelo menos duas 
visões de mundo diferenciadas, visto que a instituição escolar foi criada nos moldes da sociedade envolvente e passa então a se inserir em outro contexto intercultural. Nesse cenário, a escola é almejada, todavia a partir de dois objetivos diferenciados: a valorização do patrimônio cultural indígena e o conhecimento dos saberes científicos, para que as comunidades indígenas possam dialogar com a sociedade brasileira. Bergamaschi e Medeiros (2010, p. 61) afirmam que:

A introdução da instituição escolar no seio das sociedades indígenas, mesmo almejada por eles e inserida num processo mais amplo de organização e luta, não ocorre sem conflitos. [...] Percebe-se uma ambiguidade na visão que os indígenas têm sobre a escola, deixando antever ao mesmo tempo um "querer" e um "não querer" essa presença nas aldeias. Veem-na como uma necessidade para o diálogo intercultural [...]. Mas também, veem-na como um risco ao modo de vida tradicional [...], já que, [...] a escola é uma instituição alheia ao modo de vida dos povos indígenas e historicamente tem causado danos aos processos próprios de educação e ao uso de seus idiomas.

Nessa perspectiva, as autoras destacam os conflitos inerentes à introdução da escola em contextos indígenas, o que provoca posicionamentos diferenciados quanto ao papel da escola enquanto instituição criada pela sociedade envolvente e responsável por possibilitar o diálogo intercultural. No entanto, os povos indígenas requerem que a instituição escolar contemple os saberes culturais indígenas. Para Monte (2000, p. 19):

O conceito de currículo passa a ser explorado como o lócus em que se formam e se transformam os sujeitos dos processos escolares e suas múltiplas identidades interculturais. Essas emergem e são constantemente reposicionadas por meio das práticas discursivas elaboradas na interação com os outros, e que se materializam de forma multilíngue na e pela língua(gem).

O diálogo entre a escola e a comunidade indígena é enfatizado pela anciã do Povo Pataxó Hãhãhãi, Maria Muniz, em seu depoimento anteriormente mencionado, ao enfatizar que a escola deve trabalhar com as histórias dos anciões da comunidade local. Prosseguindo, a informante ainda destaca que:

Nós temos muitos velho... muitos anciões que têm muita história bonita e a escola ainda tá deixando a desejar... porque não tá assim... digamos... dizendo a cada época e a cada mês [...] dizendo que tem uma noite cultural pra gente tá sentado contando e conversando... cantando as nossas roda de antigamente né? [...] esse povo mais velho tem que chegar perto também da escola... pra tá lá ajudano os professores nesse sentido...

Compreende-se, portanto, a importância do diálogo entre os anciões e a escola, tendo em vista o objetivo de construir uma educação diferenciada que contemple em seu currículo, os conhecimentos socialmente construídos pela sociedade envolvente, bem como os conhecimentos locais das comunidades indígenas. Desta forma:

Os currículos escolares indígenas ganham assim um caráter de permanente movimento ondular entre aqueles conjuntos de conhecimentos 
representados como étnicos e locais, demarcadas as fronteiras entre as etnias e as línguas que falam, e a chamada "base universal do conhecimento escolar", entendidas ambas como ponto de partida e chegada para a desejada cidadania com diversidade. (MONTE, 2000, p.28)

Para tanto, faz-se necessário que a escola contemple o patrimônio cultural indígena em suas práticas pedagógicas, no qual se inclui as narrativas, enquanto mecanismo de memória individual e coletiva. No que se refere à esse aspecto, Monte (2000, p. 23) afirma que:

Ao desenvolverem atividades com a língua e a linguagem, os professores indígenas podem construir identidades multifacetadas como discurso pedagógico, nas situações didáticas propiciadas em sua formação e na de seus alunos.

Entende-se assim que o trabalho com as narrativas do povo indígena Pataxó Hãhãhãi é um tema relevante para a escola indígena da comunidade local, assim como qualquer instituição de ensino, na medida em que buscam uma educação diferenciada capaz de contemplar a cultura local e universal.

\section{CONSIDERAÇÕES FINAIS}

Conclui-se que aos povos indígenas, durante muitos anos, foram destinadas políticas que só buscavam a integração e assimilação da cultura considerada dominante. Foi a partir de lutas, que os indígenas problematizaram a situação a qual the eram destinadas, buscando construir uma educação diferenciada e baseada em seus princípios e crenças, o que ainda se constitui um desafio, tendo em vista o grande processo de assimilação e homogeneização aos quais foram expostos.

Apesar das modificações em seus modos de vida, o povo Pataxó Hãhãhãi tem buscado marcar sua diferença identitária, através da manifestação de seus valores e saberes culturais, incluindo nestes 0 ato de narrar enquanto vivência sociocultural. Nesse sentido, a narração dos contos na realidade local tem a função sociocultural de transmissão de ensinamentos e valores culturais singulares, tais como a importância da preservação da natureza, o respeito aos anciãos enquanto guardiões de memória, o perigo da vida na floresta e normas de conduta necessárias ao trabalho coletivo desta comunidade indígena.

Destaca-se assim a importância de ser organizado para o ensino formal um trabalho pedagógico que tenha como eixo os contos do povo indígena Pataxó Hãhãhãi, possibilitando as novas gerações o conhecimento de valores e saberes de seu grupo cultural, bem como o estudo da estrutura formal da língua, através do ensino/aprendizagem de gêneros e tipologias textuais. Considera-se que o trabalho com gêneros textuais narrativos poderá possibilitar aos professores indígenas a instrumentalização para a mediação entre o trabalho com a língua, através de conteúdos universais, e com os saberes culturais, através da transmissão de narrativas locais. 
Considera-se, portanto, a relevância da formação dos professores indígenas ou não, para que estes possam assumir sua função de mediador e interlocutor de sua comunidade perante a sociedade envolvente, permitindo o diálogo entre os conhecimentos ditos universais e a cultura local indígena. Por fim, espera-se que este trabalho possa contribuir para a construção de uma educação intercultural que reconheça as narrativas, os valores e as concepções do "outro" em suas diferenças culturais.

\section{REFERÊNCIAS}

ALTHUSSER, Louis; ALBUQUERQUE, Jose augusto. Aparelhos ideológicos do Estado, 6를 Edo de janeiro: Edições Graal, 1992.

ARARIPE, Fátima Maria Alencar. Do patrimônio cultural e seus significados. Revista Transinformação. Campinas, v. 16, n. 2, p. 111-122, ago. 2004.

BERGAMASCHI, Maria Aparecida. Educação Escolar Indígena: um modo próprio de recriar a escola nas aldeias Guarani. Cadernos CEDES, Campinas, v.27, n.72, p.197-213, ago. 2007.

BERGAMASCHI, Maria Aparecida; MEDEIROS, Juliana Schneider. História, memória e tradição na educação escolar indígena: o caso de uma escola Kaingang. Revista Brasileira de História, São Paulo, vol. 30, no 60, pp. 55-75, 2010.

BRASIL, Constituição. Constituição da República Federativa do Brasil. Brasília, DF, Senado, 1988.

BRASIL, Ministério de Educação e do Desporto. Lei de Diretrizes e Bases da Educação Nacional. 5. Ed. Brasília: Congresso Nacional, 2010, 60p.

BRASIL. Ministério da Educação. Referenciais para a formação de professores indígenas. Secretaria de Educação Fundamental. Brasília: MEC; SEF, 84p., 2002.

BRASIL. Ministério da Educação. Referências para a Formação de Professores Indígenas. Brasília/DF: MEC/SECAD, 2005.

CAMARGO, Dulce Maria; ALBUQUERQUE, Judite. Projeto Pedagógico Xavante: tensões e rupturas na intensidade da construção curricular. Cadernos CEDES, Campinas, v23, n.61, p.338-366, dez. 2003.

CAVALCANTE, Lucíola Inês Pessoa. Formação de professores na perspectiva do Movimento dos professores indígenas da Amazônia. Revista Brasileira de Educação, Jan-abr., noㅡ 22, p. 14-24, 2003.

DÍAZ BARRIGA, A. (2006). La educación en valores: Avatares del currículum formal, oculto y los temas transversales. Revista Electrónica de Investigación Educativa, 8 (1). Consultado el 28 de septiembre de 2017 en: http://redie.uabc.mx/vol8no1/contenido-diazbarriga2.html FREIRE, Paulo. A Pedagogia da esperança. 1ํㅡㄹ ed., Rio de janeiro: Paz e Terra, 1992. FREIRE, Paulo. A Pedagogia do Oprimido. 46 ed., Rio de janeiro: Paz e Terra, 2005. HALBWACHS, Maurice. A memória coletiva. São Paulo: Centauro Editora, 2003. 
JUSTO, Rosangela Ribeiro da Silva. Sol e Lua: Reflexos das mudanças sociais no mito Cosmogônico do Povo Aikanã. 2012. 114 f. Dissertação (Mestrado Acadêmico em Letras) - Universidade Federal de Rondônia, Rondônia, 2012.

LANGDON, Ester J. A Fixação da Narrativa: Do mito para a poética de literatura oral. Revista Horizontes Antropológicos, Porto Alegre, ano5, n12, 13-36, dez. 1999.

LE GOFF, Jacques. História e Memória. Campinas: Ed. UNICAMP, 1994.

MONTE, Nietta L. Os Outros, Quem Somos? Formação de Professores Indígenas e Identidades Interculturais. Cadernos de Pesquisa, Rio de Janeiro, n. 111, pp. 7-29, dez. 2000. MONTE, Nietta Lindemberg. Os outros, quem somos? Formação de professores indígenas e identidades interculturais. Cadernos de Pesquisa, no 111, p. 7-29, dezembro, 2000.

OLIVEIRA, Luiz Antonio de; NASCIMENTO, Rita Gomes do. Roteiro para uma História da Educação Escolar Indígena: Notas sobre a relação entre Política Indigenista e Educacional. Revista Educação e Sociedade, Campinas, v.33, n. 120, p. 76. PELEGRINI, Sandra S.A.; FUNARI, Pedro Paulo. O Que é Patrimônio Cultural Imaterial. São Paulo: Editora Brasiliense, 2008. (Coleção primeiros passos, v.331). SEVERI, Carlo. Cosmologia, crise e paradoxo: da imagem de homens e mulheres brancos na tradição Xamânica Kuna. Revista Mana, Rio de Janeiro, v. 6, n. 1, p.121-155, abr. 2000. SOUZA, Gabriela Barbosa Souza. Os Contos do Povo Indígena Pataxó Hãhãhãi: Um Diálogo Intercultural. 2016. 205 f. Dissertação (Mestrado Acadêmico em Educação) - Universidade Estadual de Feira de Santana, Bahia, 2016.

WEIGEL, Valéria. Os Baniwa e a Escola: sentidos e repercussões. Revista Brasileira de Educação, Rio de Janeiro, n.22, p.5-13, abr. 2003. 